\title{
Pneuma: entrepreneurial science in the fight against the COVID-19 pandemic - a tale of industrialisation and international cooperation
}

\author{
José M. Mendonça \\ jose.m.mendonca@inesctec.pt | INESC Technology and Science, Faculty of Engineering, University of \\ Porto, Campus da FEUP, Rua Dr. Roberto Frias, Porto, Portugal \\ Nuno Cruz \\ nuno.cruz@inesctec.pt | INESC Technology and Science, Faculty of Engineering, University of Porto, \\ Portugal \\ Daniel Vasconcelos \\ daniel.m.vasconcelos@inesctec.pt | INESC Technology and Science, Faculty of Engineering, University \\ of Porto, Portugal \\ Carla Sá-Couto \\ csacouto@med.up.pt | Biomedical Simulation Center, Faculty of Medicine of University of Porto; Center \\ for Health Technology and Services Research (CINTESIS), Porto, Portugal \\ António P. Moreira \\ antonio.p.moreira@inesctec.pt | INESC Technology and Science, Faculty of Engineering, University of \\ Porto, Portugal \\ Paulo Costa \\ paulo.j.costa@inesctec.pt | INESC Technology and Science, Faculty of Engineering, University of Porto, \\ Portugal \\ Hélio Mendonça \\ helio.mendonca@inesctec.pt | INESC Technology and Science, Faculty of Engineering, University of \\ Porto, Portugal \\ Ariane Pereira \\ ariane.pereira@inescbrasil.org.br | Universidade Federal de Santa Catarina, Florianópolis; INESC P\&D \\ Brasil, Brazil \\ Zakaria Naimi \\ naimi@iresen.org|Green Energy Park (IRESEN, UM6P), Morocco \\ Vladimiro Miranda \\ vladimiro.miranda@inesctec.pt | INESC Technology and Science, Faculty of Engineering, University of \\ Porto, Portugal; INESC P\&D Brasil, Brazil
}




\section{Letter from Academia}

Abstract. When the COVID-19 pandemic hits Portugal in early March 2020, medical doctors, engineers and researchers, with the encouragement of the Northern Region Health Administration, teamed up to develop and build, locally and in a short time, a ventilator that might eventually be used in extreme emergency situations in the hospitals of northern Portugal. This letter tells you the story of Pneuma, a low-cost emergency ventilator designed and built under harsh isolation constraints, that gave birth to derivative designs in Brazil and Morocco, has been industrialized with 200 units being produced, and is now looking forward to the certification as a medical device that will possibly support a go-tomarket launch. Open intellectual property (IP), multi disciplinarity teamwork, fast prototyping and product engineering have shortened to a few months an otherwise quite longer idea-to-product route, clearly demonstrating that when scientific and engineering knowledge hold hands great challenges can be successfully faced.

Keywords. Technology-Transfer; Open Intellectual Property; Medical Device; Self-inflating Manual Resuscitator; Emergency Ventilator; COVID-19 Pandemic.

Cite paper as: Mendonça, J.M., Cruz, N., Vasconcelos, D., Sá-Couto, C., Moreira, A.P., Costa, P., Mendonça, H., Pereira, A., Naimi, Z., Miranda, V., (2020). Pneuma: entrepreneurial science in the fight against the COVID-19 pandemic - a tale of industrialisation and international cooperation - Letter from Academia, Journal of Innovation Management, www.open-jim.org, 8(4), 3-25. 


\section{The strength of endogenous competencies}

The investment in science and technology that Portugal has consistently pursued for the last three decades, along with the opening of the access of the higher education system to an increasing number of students, resulted in a highly-qualified young population in many areas where European and global labour markets are under pressure. This is the case of biotech and health, as well as computer science and almost all engineering domains.

One decade ago, during the turmoil caused by the global financial crisis, many young talented people left the country looking for better job opportunities, but those who stayed had a critical role in the transformation of the economic fabric of the country and in the economic recovery that followed. Exports of goods and services raised from $27 \%$ to $44 \%$ of the GDP in a decade (20092019) and high-tech European companies found out a better deal than recruiting Portuguese talent to their main sites in central and northern Europe: they started investing in their own design, product development and research and innovation centres in Portugal.

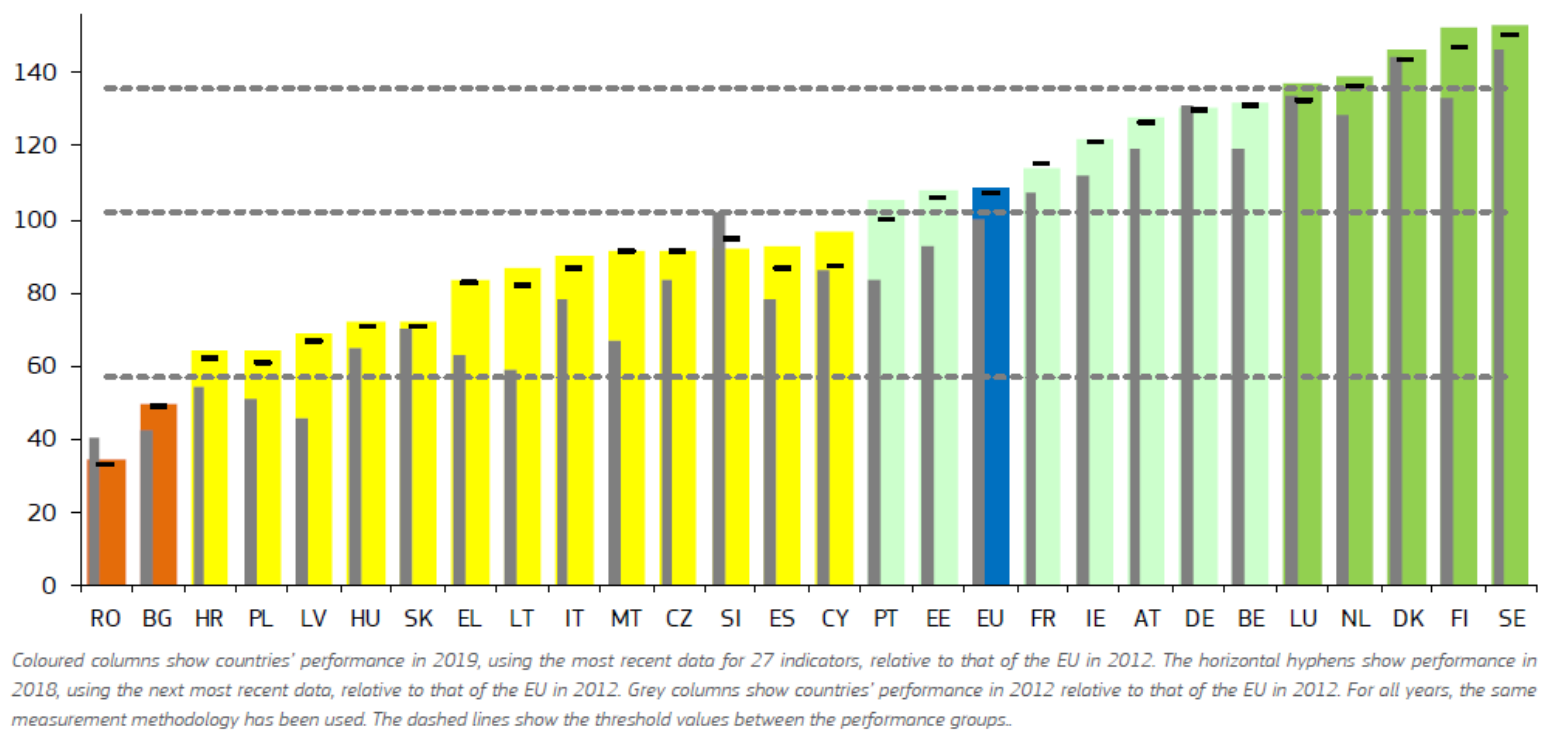

Fig. 1. European Innovation Scoreboard $2020^{1}$

The impact of all this was felt in terms of the increase in qualified employment and technical exports and a decrease in public/state debt, as the numbers for 2019 clearly show. The EU Innovation Scoreboard 2020 portrays such progress, placing Portugal in the group of countries labelled as Strong Innovators (Fig. 1). The criteria in which Portugal performed better were innovating SMEs, innovation-friendly environment, attractive research systems and human resources. The potential behind all that lies in highly-qualified people and in an increasing number of companies and institutions, such as universities and research labs, building a dynamic innovative fabric. They all compete globally in their specialization domains, making the most

$\overline{1}$ https://ec.europa.eu/commission/presscorner/detail/en/QANDA_20_1150 
of their scientific and technical knowledge, international networking, design competences and manufacturing capabilities.

\section{Fighting the pandemic with knowledge-based innovation}

When the COVID-19 pandemic hit the country in early March 2020, some of these companies and research and innovation institutions became restless and refused to be kept hostage of the situation. Initiatives emerged everywhere in the country, with many offering their competences and effort pro-bono to help fighting the pandemic and the awful consequences that were already being perceived. Many of these bottom-up initiatives tried to alleviate the pressure on the health care system, responding to the needs of medical doctors, nurses, hospitals and the health authorities. These initiatives ranged from helping in the design and manufacturing of masks and visors for the personal protection of the health personnel to offering new ways of testing for COVID-19 infection and actually increasing the country's daily testing capacity. Privacy-preserving digital contact tracing applications were also developed and deployed by leading research institutions and technological start-ups, as the Portuguese STAYAWAY COVID and many others in Europe. The design and manufacturing of ventilators to help in possible extreme situations, as those that unfortunately had occurred in other European countries, was also an endeavour pursued by both companies and research labs.

As always, people are key in facing new challenges. Medical doctors, engineers and researchers that knew and trusted each other rapidly brought-up informal networks to start cooperating right at the beginning of the imposed isolation period in mid-March 2020. The so-called OpenAir initiative was launched, rapidly becoming an attractor for the willingness and drive of many researchers in the world. A small team was built around a group of INESC TEC ${ }^{2}$ researchers in robotics, with medical doctors, engineers and experts in regulatory matters. They all wanted to contribute to Open-Air, but when the initiative grew out of proportion, networking many hundreds of people, and the management model became too complex, they had a feeling that the outcome of all this generous effort would risk arriving too late to help fighting the pandemic.

Knowing all these efforts in the Open-Air initiative, the Northern Region Health Administration (ARS-Norte) has contacted the group at INESC TEC with the challenge: would they be able to develop and build, locally and in a short time, a ventilator that might eventually be used in extreme emergency situations in the hospitals of northern Portugal? This was the beginning of Pneuma.

The COVID-19 pandemic reached Portugal first with imported cases in the north of the country. The first cases seem to have been people that have returned from northern Italy, where they had been for business or leisure. The north of Portugal is a very industrialized region with a dense business network with northern Italy, namely in shoes, textile and garments, and also with China. Furthermore, many Portuguese working in several European countries returned home in March, when the companies that employed them closed because of the pandemic. In

$2 \quad$ INESC TEC is a leading research and technology transfer institute whose associates are the University of Porto, INESC, Porto Polytechnical School, University of Minho and University of Trás-os-Montes and Alto-Douro. 
spite of all the efforts of the authorities, the local transmission lines have rapidly multiplied the number of infected people and the north of Portugal became the region with the higher number of COVID-19 incidence. And, as everywhere else in Europe, there was a grounded fear that extreme cases of lack of ventilators in the intensive care services of hospitals might occur, particularly in a scenario of increasing worldwide scarcity. This was a valid and pressing concern to the Portuguese National Health Service, considering that, at that time, less than 1400 ventilators were available to the entire population.

\section{Two weeks of creative excitement leading to the first Pneuma prototype}

In the summer of 2019, students of the Rice University (USA) had developed a prototype of a basic ventilator based on an automated self-inflating resuscitator that would suit itself to be manufactured and assembled in developing countries, whose health systems could not afford full featured Class IIb intensive care ventilators costing between 20 and 30 thousand dollars. Their design was openly available at Rice University's website and it seemed to be easy to replicate, even in a scenario of forced confinement, since it could be assembled from ubiquitous components in robotics laboratories.

The team started to work enthusiastically, zooming for technical discussions and work organisation. At first, the "lab" to design and build prototypes was in fact spread over a few garages, because all the labs at INESC TEC and at the School of Engineering of the University of Porto were closed. It was just like the birth of the automotive and computer industries inside the inventor's garages. The mechanical concept was validated in a few days and the first prototype was designed using plain Solidworks, aiming at simplicity and having in mind that parts were either to be produced with 3-D printing or they should be found easily in hardware stores, that is without relying on any complex, eventually highly uncertain, global supply chain. The first full-featured working prototype was reached on March 25th, following to ten days of intensive work. ARS-Norte experts and the doctors in the team validated this first milestone output and set the encouragement to pursue the development. At the same time, these interactions were most helpful to refine the main features of the device, pursuing a trade-off between usefulness and feasibility in a short timeframe. In short, there were three main features that the user would be able to set:

- Respiratory rate, from 8 to 30 BPM (breaths per minute)

- Inspiratory volume, from $250 \mathrm{ml}$ to $700 \mathrm{ml}$

- Inspiration/Expiration Ratio, from 1:1 to 1:4 


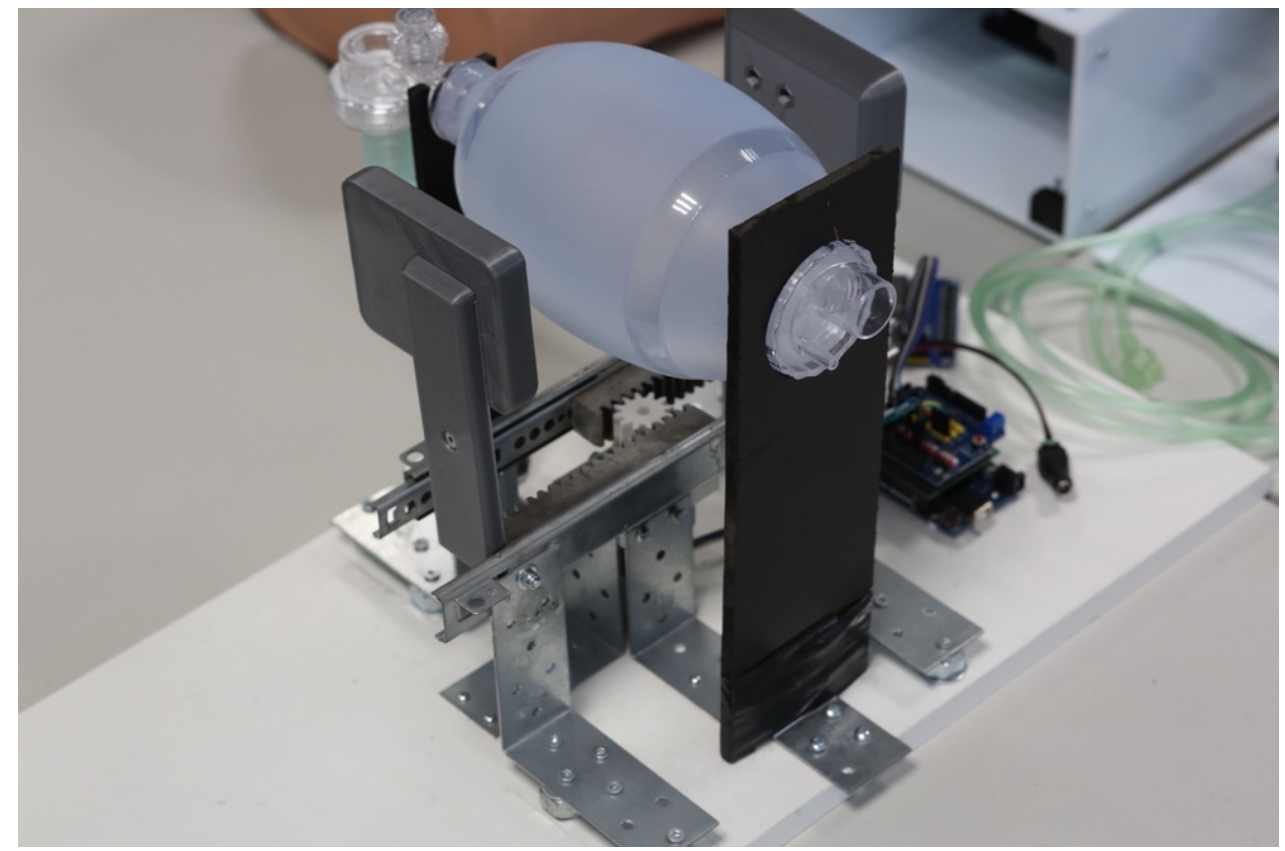

Fig. 2. First demonstration prototype assembled in 3 days

\section{Proof-of-concept and pre-clinical testing}

Pneuma ${ }^{3}$ automates the manual operation of a self-inflating manual resuscitator. Using a computer to control timing and motion parameters ensures unmatched accuracy and repeatability. The main idea is not to replace any medical equipment, but simply to ensure that the pre-existing medical equipment - the self-inflating manual resuscitator - is correctly used offering a set of features inaccessible to manual operation. The risk is inherently low and the design allows for a simple removal of the resuscitator from the stand to resume manual operation or replace it by another device in case of need.

The principle of operation of Pneuma is quite simple, since it is based on a single vertical motor. As the central pinion rotates, two parallel racks move in opposite directions, causing the "arms" to close or open, therefore squeezing or releasing the self-inflating resuscitator. The inspiration volume depends on the length traversed by the racks and all motion parameters are controlled by an Arduino Uno, a very popular low-cost microcontroller (Fig.2).

With a reliable working prototype in hands, the forthcoming steps regarded pre-clinical testing. With the guidance of the Director of the one of the UP medical schools (FMUP), the team has been directed to the Biomedical Simulation Centre of this medical school and to the major city hospital in Porto (CHUSJ). A carefully designed testing protocol was applied in two phases: (i) Functionality and performance testing, and (ii) Usability testing. Extensive testing with lung models and full-body patient simulators was undertaken with the collaboration of healthcare professionals with extensive expertise in critical care and artificial ventilation. This resulted in

3 https://pneuma.inesctec.pt/en/pneuma/ 


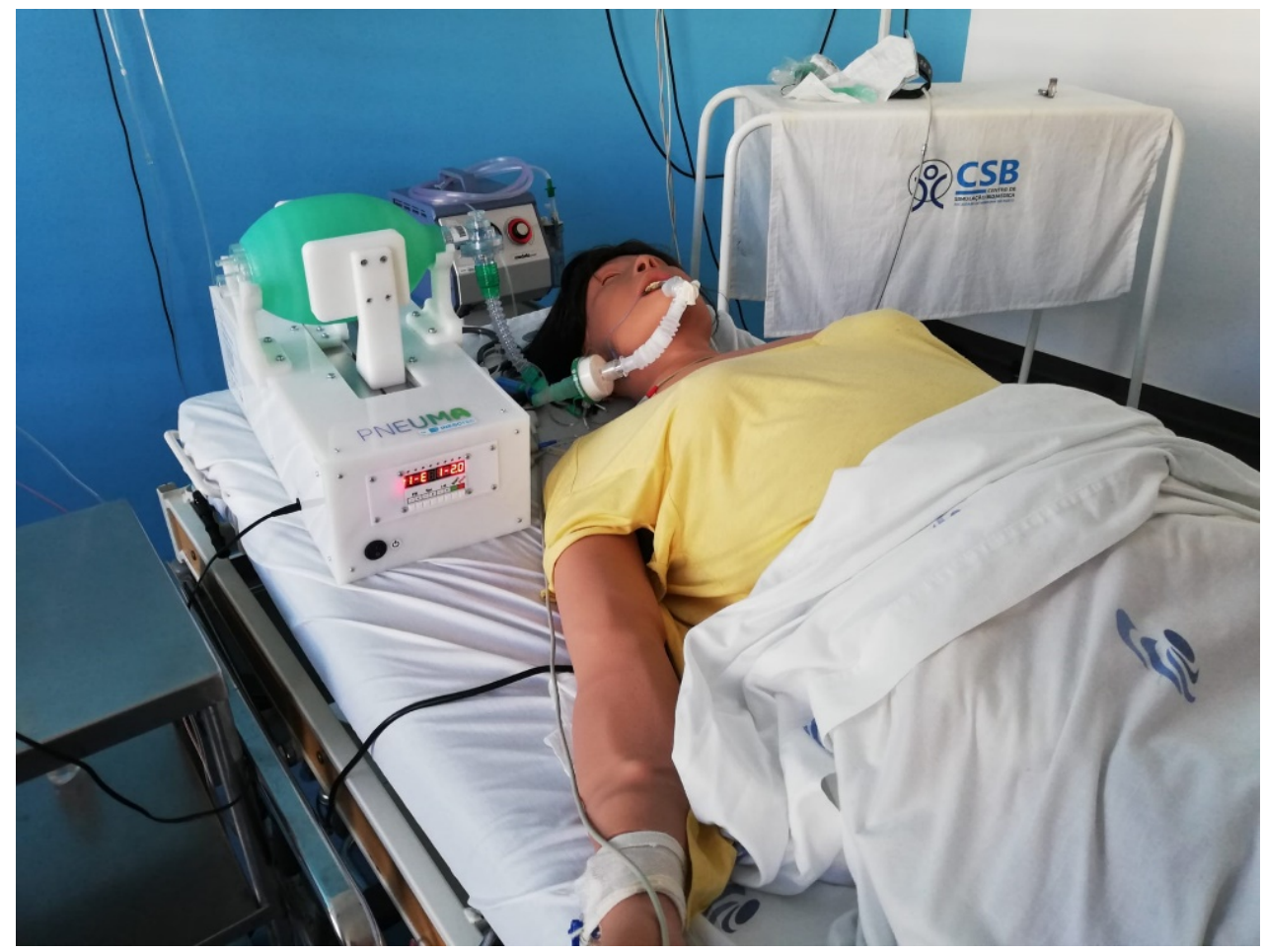

Fig. 3. Pneuma being tested coupled to a full-body patient simulator at the Biomedical Simulation Center of the Medical School of University of Porto

considerable progress through the calibration and control of variables relevant to the main modes of operation of Pneuma. Informal tests have also been undertaken in the simulation centre of the other UP medical school (ICBAS) and of another major Porto hospital (CHUP) (Fig. 3).

The Pneuma design optimisation pursued in parallel, taking into account all the feedback from pre-clinical testing and also looking forward to the following stage: manufacturing of a pre-series of units for more intensive testing, namely clinical trials, and stepping up in a roadmap for industrialisation.

\section{The tough certification roadmap of an invasive pandemic venti- lator}

In addition to the technical and logistic challenges associated with the rapid development of a ventilator, regulatory affairs have to be dealt with. Treating patients and saving lives is noble but also requests manufacturers to demonstrate that their products - ventilators in this case perform and are safe. But although many countries have agencies to regulate and oversight the use of medical devices with established procedures to assess new medical devices, the COVID-19 pandemic was challenging them to the extreme. In fact, COVID-19 created new problems to regulatory affairs, where "by-the-book" solutions do not work. 
As a medical device, Pneuma requires clearance or approval by Governmental agencies, such as INFARMED in Portugal or FDA in the US, to be used by healthcare professionals. As previously described, Pneuma is coupled to other medical devices - a self-inflating manual resuscitator with valve and mask, or for short Bag Valve Mask (BVM). This fact raised the question whether or not Pneuma would be just considered a medical device accessory, as it "simply automates" the operation of a BVM which is used manually in a daily-basis by doctors and nurses. In the medical device arena, the intended use and the features have nevertheless a huge impact on the regulatory pathway that should be followed. This is why Pneuma's team integrated, from day one, people with expertise in regulatory affairs to help in the definition and selection of the technical features, such as the alarms, electromagnetic compatibility or the materials used. But the truth is that, at that time, the regulatory pathway was not at all clear.

As the initiatives to manufacture medical equipment and devices in short supply worldwide emerged, the uncertainty on how national authorities should deal with them increased. At that time, experts in the medical devices industry argued on how inexperienced manufacturers (including R\&D institutions and Universities) would overcome technical, logistical, and regulatory hurdles in time.

The first guidance in this field was published by the World Health Organization (WHO), providing technical specifications for ventilators, detailing the major technical features (e.g. tidal volume, pressure, alarms), and pointing to the international standards ISO 80601-2-80 and ISO 80601-2-79 to be followed. A few weeks later, the Medicines \& Healthcare Products Regulatory Agency in the UK (MHRA) developed and disclosed a comprehensive document with guidance to the manufacture of ventilator systems. This document, that was mostly in line with the WHO guidance, was key to the development of Pneuma. Many of the technical specifications suggested in the MHRA's document corroborate the feedback that Pneuma's team had obtained from the medical experts, and not just those that joined in. In fact, MHRA's guidelines led to adding a pressure sensor and an alarm to Pneuma, two features contributing to the overall safety of this medical device.

In addition to the above referred guidelines, National Health Authorities around the world tried to support these initiatives while ensuring the safety for the patients and the rights of the players already in the medical devices market. The short time interval until the peak demand for ventilators led National Health Authorities to recognize the impossibility of new medical devices to be certified and cleared/approved in time of being useful in the pandemic. Thus, "Emergency Use Authorization" routes were opened by FDA, MHRA, and other National Authorities as the Portuguese INFARMED. The special procedure created by INFARMED also relaxed some requirements considering the lack of experience of this "new manufacturers", like Universities and research labs.

Among the initiatives for the urgent development of ventilators in Portugal, Pneuma was the only one not aiming at the commercialisation of the ventilator after the end of the pandemic. This feature had a positive impact on INFARMED, which looked favourably on the fact that a control of devices per hospital and subsequent recall at the end was planned. However, the special regime created was intended to create a 6 -month time window, during which the medical device would enjoy a conditional authorisation after a positive opinion from the Task Force of 
experts, seeking that the device would subsequently follow the normal regulatory pathway. The regulatory barrier and its certification requirements were always high, which is understandable considering the intended use, but made it difficult for entities that did not have commercial purposes, were unfamiliar with the regulatory framework or did not have the means to obtain the various certifications required.

Pneuma operation fits under these "Emergency Use Authorization" routes, as it specifically addresses the shortage of ventilators in Portuguese hospitals during the COVID-19 pandemic. This limitation in time and location helped the risk assessment carried out by INFARMED, since there is actually no intention to place the present version of Pneuma in the market.

The Pneuma's team and its consultants on regulatory affairs believe that this ventilator is a risk class I (Europe) medical device since it is non-invasive. The contact with the patient is made by the BVM, as well as all the components that ensure some important functions (HEPA filter, endotracheal tube and PEEP valve). In addition, the Pneuma can be stopped and replaced by any healthcare professional at any time, as its use is temporary. The possibility of Pneuma not being considered a medical device but a ventilator accessory became increasingly difficult as the various National Authorities only approved masks, tubing and humidifiers as accessories.

INFARMED was responsive to the arguments of the Pneuma team but, in their view, this ventilator is risk Class IIa (Europe) because even though it is not invasive, the Pneuma has a series of electronic components that appeal to the regulations applied to this more demanding risk class. The costs associated with the testing, certification and approval of a Class IIa device are about 10x higher than those of a Class I device, thus presenting as a major barrier. While a Class I device dossier is self-reported, a Class IIa dossier requires testing in animal models, usability testing with healthcare professionals and eventually clinical trials.

Between 25 March 2020 and 2 August 2021, 81 ventilators were granted Emergency Use Authorisation by the $\mathrm{FDA}^{4}$. It should be noted that all of them were manufactured by a commercial entity. The Apollo ABVM ventilator is a direct descendent of the University of Rice project and has been cleared with Stewart \& Stevenson Healthcare Technologies, LLC as the manufacturer.

Taking all these lessons into consideration, a dossier is being prepared with all the relevant results for certification and analysis by notified bodies, in which case the partnership with a manufacturer with prior knowledge, experience and success in having medical devices cleared or approved is of paramount importance.

\section{From prototypes to pre-series and to industrial production}

The development of the first Pneuma prototypes occurred during a steep rise in the number of COVID-19 patients in intensive care units, particularly in the northern region. At the time, there was a shortage of available ventilators in these units, with the chances of emergency devices being needed being very high. The local health authorities defined a total number of 200 units

\footnotetext{
4 https://www.fda.gov/medical-devices/coronavirus-disease-2019-covid-19-emergency-use-authorizations-medical-devices/ ventilators-and-ventilator-accessories-euas\#accessories
} 
as a safety quantity to have available for local hospitals, and the Pneuma team evaluated the options to produce such quantity.

In order to proceed with this sizeable replication, the mechanical design had to be modified. The initial prototypes were assembled from a combination of 3d-printed parts which took about 60 hours per unit to print. Even with the availability of a large number of 3d-printers, it was not feasible to manage the supply of thousands of parts, neither to ensure an even level of quality. On the other hand, the planned quantities were insufficient to justify the costs of using injection moulding technology, the solution for mass production of many thousands. For these reasons, the choice was to rely on CNC machining, offering high repeatability and fast delivery, yet at a higher cost. This required the redesign of many parts to simplify machining and reduce production time and cost. As opposed to additive manufacturing, CNC machining costs are reduced with larger parts (less time spent in removing material), and therefore the final assembly product resulted in heavier Pneumas. The choice of materials was a combination of polyacetal (POM) and highdensity polyethylene (HDPE), depending on the required hardness/compliance of each part. In total, each Pneuma has 26 parts machined from these engineering plastics, with 10 different part designs. Two main exceptions were the rack and pinion system, machined from commercial steel components, and the motor mount, manufactured from sheet stainless steel to further reduce cost and improve electromagnetic shielding. To preserve the design simplicity, the overall housing was assembled from planar faces, laser cut from cast acrylic sheets (PMMA).

In spite of the inherent difficulties in industrial production, this process started in the beginning of April'20, with the country plunged into emergency state and under strict confinement rules. Many companies had halted production, while others had severe shortage of human resources. Component suppliers were facing similar difficulties, as well as longer delivery times due to the constraints imposed on shipping companies. All this presented additional challenges in terms of supply chain, which were particularly demanding for the supply of electronic components, as most of them had to be imported, some from Asia. Fortunately, within the network of partners built through the participation in multiple projects, it was possible to ensure all the supply chains for the delivery of all components in just a few days. Since the Pneuma was a pro-bono initiative, most of the companies involved in the production of the units contributed by offering their products or services with no profit margins.

INESC TEC network was also fundamental to reach SELT, a company based in the centre of Portugal, specialized in contract assembly services for different types of equipment, namely medical devices. Their experience and expertise were fundamental to overcome the challenge of rapidly transferring the assembling know-how with minor physical interactions. Even with reduced personnel, SELT committed to initiate production by the end of April, proceeding with the delivery of 50 units per week since the first week of May. Before initiating production, a pre-series batch of 10 units was assembled to validate the new designs and all the assembly procedures. This batch was split, with 6 units being assembled by SELT and 4 at INESC TEC, with the final verification successfully completed by the end of April.

The most frequent comment from the doctors who tried the earliest Pneuma prototypes regarded the absence of information about the pressure of the air in the patient airways. Such parameter is of extreme value in assessing the capacity of the patient to absorb oxygen. Another aspect 
that could approximate Pneuma to traditional ventilators was the introduction of further safety mechanisms through a set of alarms to detect abnormal conditions, such as power failure or mechanical blockage. So, in parallel with the earliest stages of production, these two extra functionalities were also considered and included in the revised design. The incorporation of both the pressure sensor and the alarms for abnormal situation detection was planned and implemented as to cause minimum impact on the assembly process but also to facilitate the upgrade of the units that were already assembled when this new design was validated.

\section{A global medical device with pro bono engineering by design}

\section{- The VITA PNEUMA solution in Brazil}

The value of structured international cooperation was successfully put to the test when INESC $\mathrm{P} \& \mathrm{D}$ Brasil $^{5}$ was challenged to join in the efforts to disseminate the Pneuma concept. INESC TEC provided full access to all technical documentation and manufacturing designs, as well as a forum of free discussion and technical guidance.

Meanwhile, INESC P\&D Brasil had launched the FASTEN VITA initiative, as a voluntary project to help the health agents in the fight against the pandemic. The purpose was to develop products, adjusted to allow fast and decentralized manufacturing. Under INESC P\&D Brasil coordination and the Governmental support through RNP (the National Research Network), more than 40 researchers, from 12 Brazilian universities and working pro-bono, joined in. And the core catalyser of the initiative became the Pneuma.

But the Pneuma challenge, from an innovation translation point of view, was way beyond a simple transfer of the concept. Deep reengineering had to be done, to allow for the following factors:

- Unavailability of components, either electric, electronic or mechanical, in Brazil, that had been adopted in the original Pneuma

- Unsuitability of the manufacturing process devised for Pneuma in the Brazilian context

- Requirements placed by the health authorities in Brazil (such as ANVISA, the National Agency for Sanitary Surveillance, with regulatory powers), distinct from the ones found in Europe.

With this reengineering, the VITA PNEUMA ${ }^{6}$ was born (Fig. 4).

The device, under Brazilian regulations, can only be classified as an automated life support system. It is projected to allow teams from hospitals and basic health units to provide non-invasive respiratory support to patients, until they may be transferred to conventional ventilators.

$5 \quad$ INESC P\&D Brasil is a sister organization of INESC TEC in Brazil, with headquarters in the state of São Paulo and encompassing nine Federal Universities plus INESC TEC from Portugal as associates, plus some additional ten universities included in the denominated Network INESC Brasil.

6 https://fasten-vita.inescbrasil.org.br/conheca-o-projeto/ 


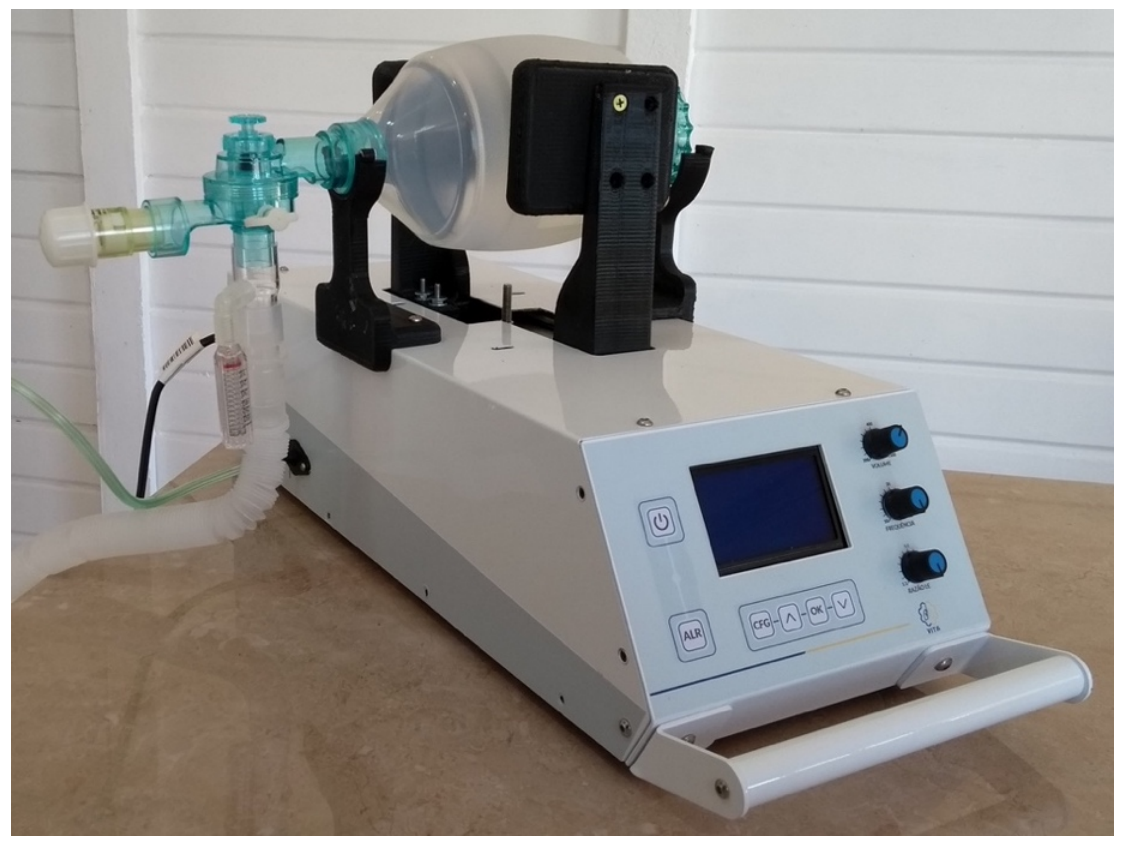

Fig. 4. Vita Pneuma, developed and adapted by INESC P\&D Brasil from the original Pneuma design

Some technical characteristics are:

- air or air $+\mathrm{O}_{2}$ volume: between 200 and $600 \mathrm{ml}$ per cycle

- frequency: between 10 and 30 breath cycles per minute

- inspiration/expiration (I/E) ratio: from 1:1 to 1:3

- positive pressure in patient's airways: up to $20 \mathrm{cmH}_{2} \mathrm{O}$

- monitoring of parameters - PEEP and PIP

- safety controls: excessive pressure in airways; alarms for patient condition of equipment malfunctioning

- exhaled gases: HEPA filtered before releasing in the environment

- medical certifications: all parts in contact with the patient breathing

- testing: the equipment was fully tested in a Laboratory certified by ANVISA.

- display: a set of alarms, measurements and operator controls

A remarkable trait of the VITA PNEUMA is the manufacturing process put in place. After the design phase, departing from the Pneuma plans supplied by INESC TEC, a manufacturing and assembling phase ensued. The parts were built by 3D printers, laser cutting or machining equipment. Individuals, companies, or laboratories involved were the ones who voluntarily offered the produced parts. Thus, the locations where products could be manufactured were multiplied. 
With the 3D printers connected to the FASTEN Vita network, they could receive tasks to perform, directly from the network server. In addition to dispatching tasks, the server also optimized geographic distribution between manufacturing points, allowing the operator to meet regional demands. In this way, time was saved by manufacturing the products in the places closest to where they were demanded, and by the adhesion of the volunteers, scale was also gained. This scaled up production was possible due to the Industrial Internet of Things (IIoT) platform developed by INESC P\&D Brasil in the context of FASTEN, an R\&D project under the EU-Brazil programme, within Horizon 2020 and Brazilian Government support, initially involving companies such as Embraer and Thyssenkrupp, in Brazil. On the European side, INESC TEC is also a key partner in the FASTEN project.

The IoT platform put up in Brazil by the FASTEN project enables a "production line" or "virtual factories" for the manufacture of products in the most diverse parts of the country, composed of a large set of SAM (Smart Additive Manufacturing) units, with the possibility of easily recruiting at will tens of 3D printers for the tasks needed. The IoT platform also has optimization and simulation tools to maximize production. This platform was ready and it was natural and efficient to redirect it to the purpose of manufacturing VITA PNEUMA parts.

\section{- The iVENT solution in Morocco}

A further step in international solidarity was taken when two institutions from Morocco joined in the Pneuma initiative: IRESEN and GEP.

The extension of Pneuma to Morocco was discussed in three-party virtual workshops, joining IRESEBN and GEP with INESC TEC and INESC P\&D Brasil. Again, the challenge was to translate the concept but allow space for local innovation, and adaptation to specific conditions. Some of the constraints faced in Brazil were again met in Morocco: access to specialized components, manufacturing processes and requirements from health authorities. The evolution of Pneuma in the Moroccan context produced the iVENT solution (Fig. 5), in good faith announced in Morocco as the product of a three-country solidarity and alliance.

Some specific characteristics of iVENT are:

- newly developed customized PCB, as opposed to the original Pneuma Arduino solution, increasing the reliability, flexibility and number of functions to be embedded in the device

- integration of a Li-ion battery assuring a 3-hour autonomy, allowing the use in remote regions with unreliable power supply or in ambulances

- addition of sensors, and alarms for leakage or malfunction modes.

- integration of an interactive display with more useful medical information

- integration of an air/oxygen mixer inside the iVENT, to control mixing in the absence of availability of mixers in hospitals, a case that may happen in remote regions or when under a surge of demand

- development of a different and more silent traction solution 


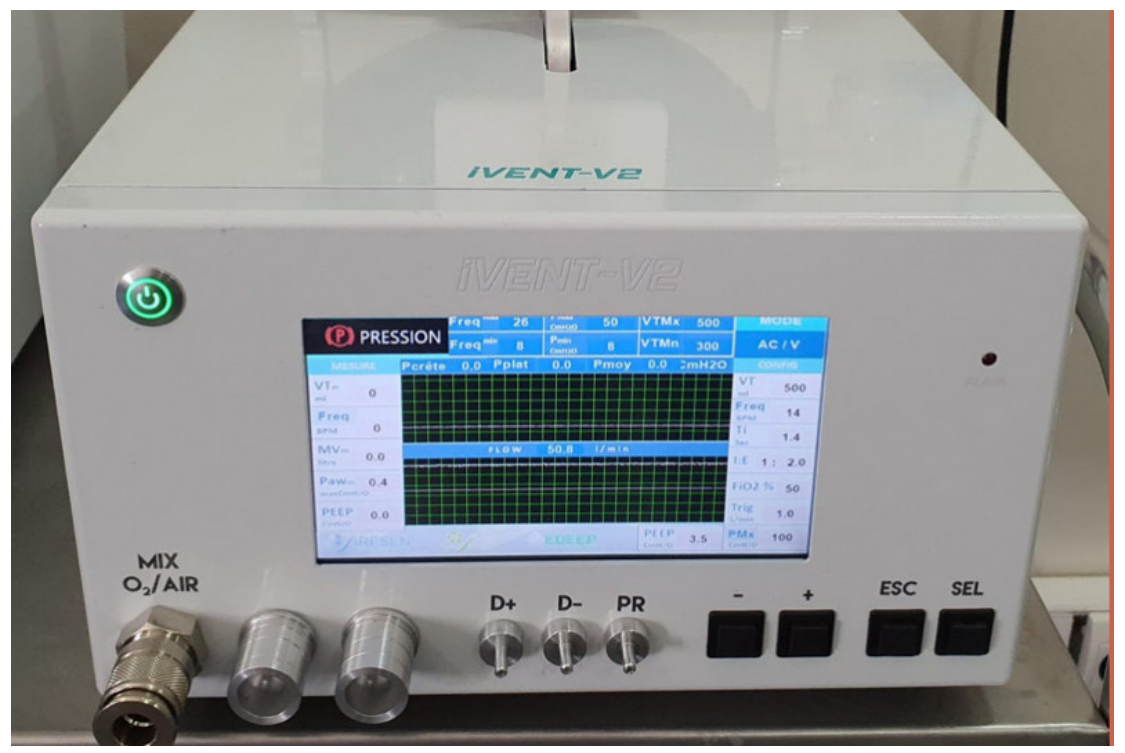

Fig. 5. iVent, developed and adapted by GEP/IRESEN in Morocco from the original Pneuma design

- development of metallic casings according to sanitary standards and the capabilities of the Moroccan industry

The iVENT solution (as well as the VITA PNEUMA solution) is a living proof that cooperation fosters innovation. Innovation brings concept to reality, and re-inventing to adapt to local conditions/constraints is a key factor for success.

\section{From the idea to the product in less than 100 days}

About three months after the beginning of the Pneuma project, 200 units were offered by the Pneuma consortium to ARS-Norte to be delivered to a number of hospitals in northern Portugal (Fig. 6). Product design, development, engineering and tests/calibration were pro bono work of the Pneuma team starting from the initial open IP. The Pneuma technology has been made public, as referred above, as open-source hardware and software ${ }^{7}$ to be freely used in countries where the need may arise.

The production cost of each of the 200 units was in the range of $300 €$ - including part purchasing and manufacturing, assembly and packaging - making Pneuma a simple to operate, versatile, inexpensive pandemic emergency ventilator. These costs have been covered by private sponsors that were engaged to the project, namely AIMMAP (Association of Portuguese Metallurgical, Mechanical Engineering and Similar Industrial Companies) and FLAD (Luso-American Development Foundation).

$\overline{7 \quad \text { Avaialble at https://pneuma.inesctec.pt/en/open-project/ }}$ 


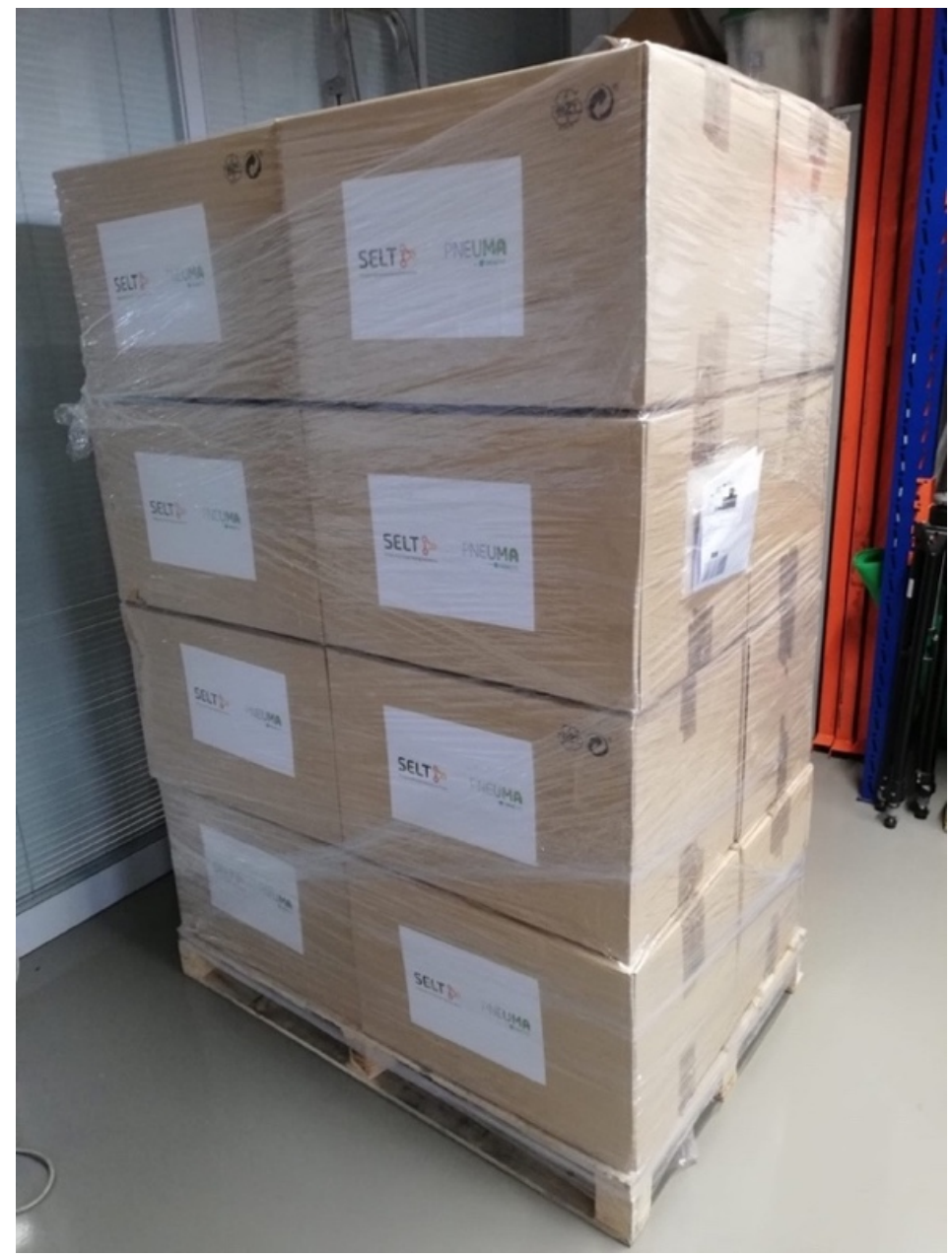

Fig. 6. The first 16 Pneuma unit's pallet delivered to ARS-Norte in June 2020.

\section{Offering value with Pneuma after the pandemic emergency}

During these 100 days, companies and research labs around the world carried out the development of technologies and products to help fighting the COVID-19 pandemic. This became a goal for many who realized that the world supply capability was not sufficient to meet the urgent needs and also that the dependence of manufacturing in China was an extremely delicate issue, especially in times of crisis. The Pneuma team kept up with many of those initiatives aiming at a similar outcome. From the many designs of emergency ventilators that emerged during the pandemic, to the best of our knowledge Pneuma was the only one that had a first prototype-toproduct engineering work and was manufactured in such a large number.

While the global offer of full-featured Class IIb intensive-care ventilators is likely to be ensured both by the take-up of companies already in the market as well as by new entrants, doubts may arise regarding the offering of low-cost emergency ventilators like Pneuma. There was no commercial offer before the pandemic and it is unsure that the world leading manufacturers of 
Class IIb ventilators selling for many thousands of euros/dollars might be interested in offering much cheaper solutions, even because these address markets in developing countries with little or no buying power.

The opportunity for Pneuma may perhaps come from a new niche market created by the needs for extra resources in intensive care units in case of a pandemic, especially in countries with very scarce health care system resources. In many of those countries, in Africa for example, local production even of a simple unit like Pneuma is not feasible and this creates an opportunity for a company willing to address those markets disregarded by leading manufacturers. A highly relevant feature for such a market is that Pneuma is a portable ventilator that can be powered by standard inexpensive 12-volt batteries, therefore being easily installed and used in an ambulance.

\section{A few technical and usability issues}

While Pneuma sparked potential interest from a medical device company which is willing to carry out the certification process, several improvements are under development within the scope of a project sponsored by the Foundation for Science and Technology, the Portuguese funding agency for science and technology activities, under the special call RESEARCH4COVID19 (project number 82).

One of the main improvements was the user interface and wireless connectivity via Wi-Fi. A PCB board with a colour LCD display and a ESP32 microcontroller that reads user inputs trough push buttons and rotate buttons was used. In figure 7, we can observe the front and the back of the developed board. The wireless connectivity allows the configuration, firmware download, tuning and monitoring of the Pneuma system. It also opens the possibility to send alarms via email or SMS, for example, and record events in a data base for later processing.

The graphical user interface allows the system to display much more information. At start-up it displays the serial number of the device, the serial number of the ESP32 firmware and the serial number of the Arduino microcontroller firmware (figure 8). During the normal utilization it displays a graphical evolution of the pressure, the air volume in each cycle, the number of respirations per minute, the I:E factor, the relationship between inspiration and expiration times, and other monitoring variables as the PIP - peak inspiratory pressure, Plat - plateau pressure and PEEP - positive end-expiratory pressure (figure 9).

Another procedure that benefited from the existence of a wireless communication with Pneuma was its testing. During the development phase, the MotorTune software application was created, which allowed not only to fine-tune the motor control process but also to monitor a set of electromechanical parameters of Pneuma during its operation (figure 10). This application running on a PC needed however to establish a serial connection with the Arduino board, something that was done through a USB cable. This need for a physical connection required opening of the Pneuma box, with all the inherent constraints.

The new version of Pneuma allows this monitoring process to be done wirelessly, and therefore without opening the box, the ESP32 being responsible for establishing the bridge between the commands sent/received from the MotorTune application by udp protocol, and the commands received/sent to the Arduino board by serial protocol. 


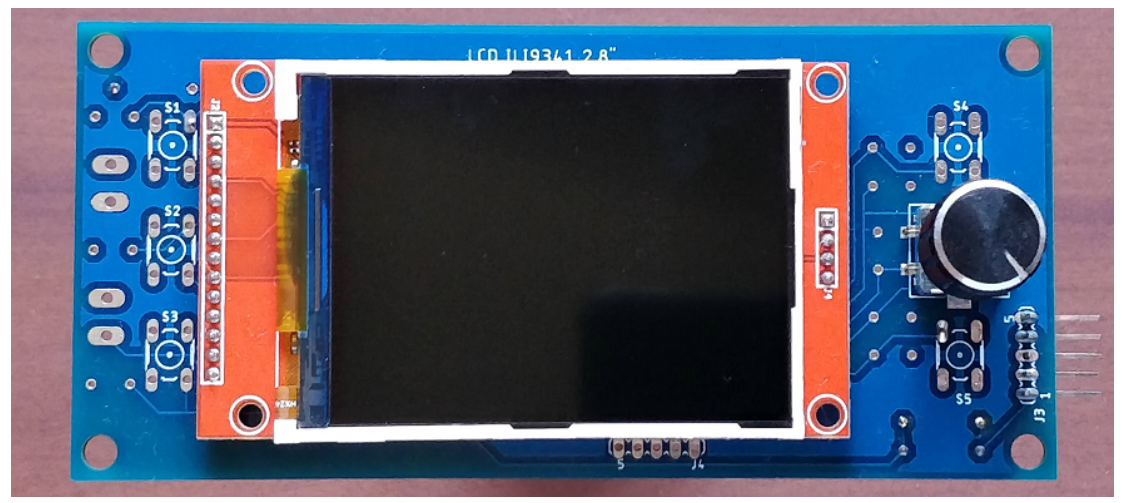

a)

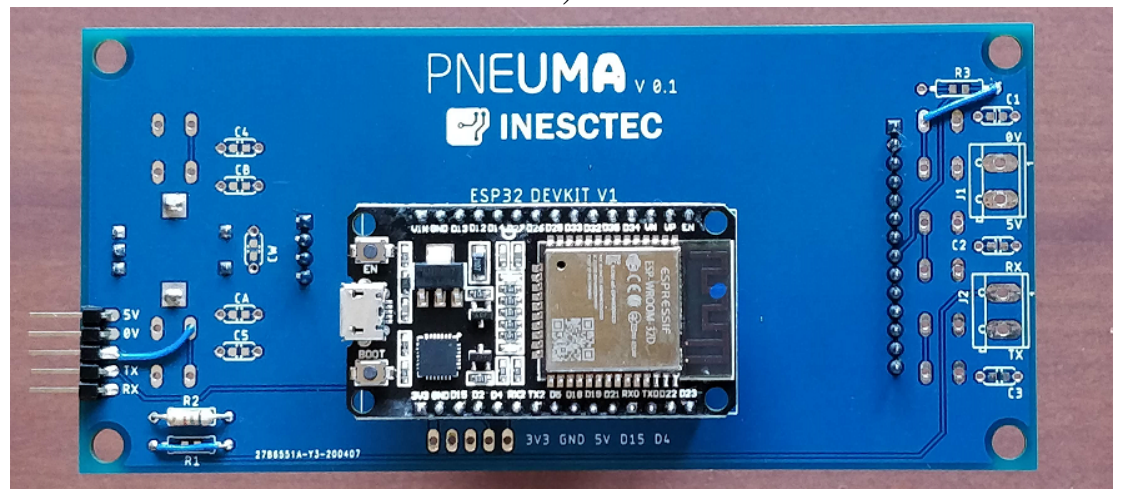

b)

Fig. 7. LCD interface and ESP32 controller with Wi-Fi, front (a) and back (b)

This functionality can only be used if a previously maintenance mode is activated on the Pneuma box, ensuring that it is not used in an intrusive way.

\section{Lessons learned}

The COVID-19 pandemic abruptly brought unprecedented challenges of a very diverse nature: scientific, economic, regulatory, ethical, social and political. Knowledge and science have been key in facing these challenges, as it had already happened in the past. But never before had scientists and engineers been challenged to transform advanced knowledge into novel effective solutions - products and services - in such an incredibly short time and racing against the pandemic.

Pneuma is a leading example of a science-based innovative product whose development, testing and manufacturing was a unique undertaking carried out by a highly capable multidisciplinary team, with many contributing in a personal capacity and all working pro bonofor a cause. Two conditions were fundamental for the success of this endeavor: the talent of the people and the capabilities of the companies and institutions and the previous experience of INESC TEC in knowledge transfer and impactful science-based innovation. 


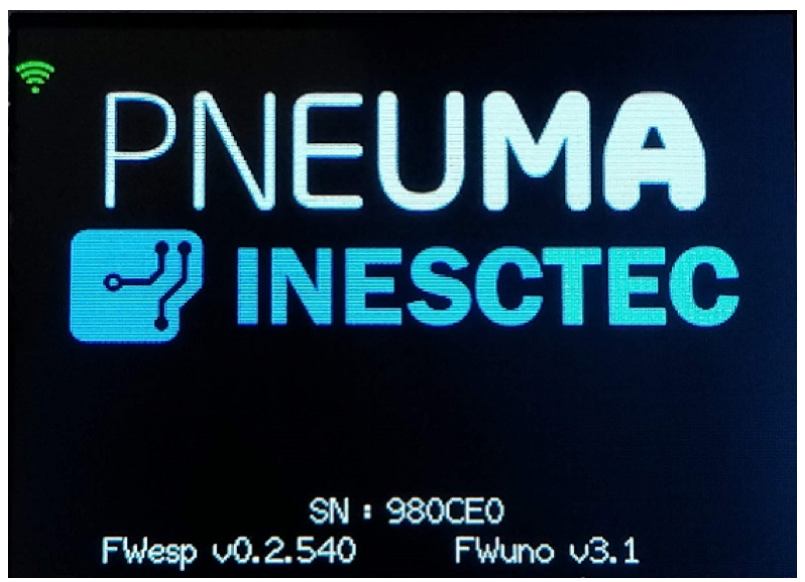

Fig. 8. Start-up information on the LCD

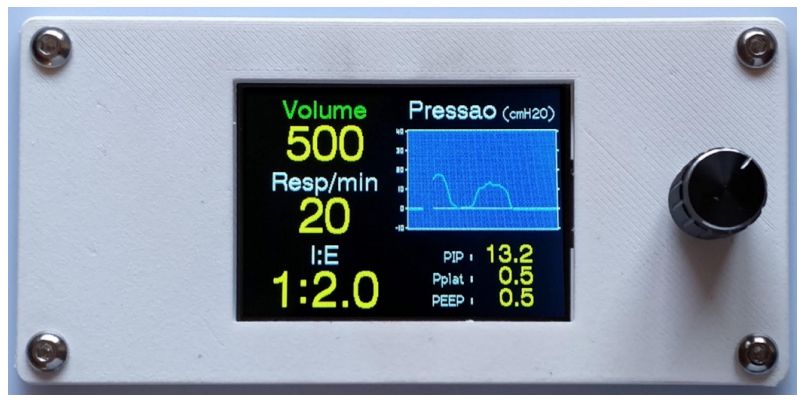

Fig. 9 - Graphical user interface and rotate button

The institution social capital, that is INESC TEC sound roots in the regional ecosystem and the capability for leveraging its national and international networks, was key to facilitate the orchestration of so many different contributions, in various engineering fields, health, regulation, certification, manufacturing, assembly, financing and dissemination of results. The well-developed dynamic capabilities have enabled the quick and effective exploitation of the emerging opportunity, mobilizing the necessary internal and external resources and even transforming itself to achieve it in a context of hard confinement.

The objectives of developing and building, locally and in a very short time, a ventilator that might eventually be used in extreme emergency situations in the hospitals of northern Portugal were fully and timely met, and the post-pandemic use of Pneuma is now being considered. As a portable affordable emergency ventilator that can be powered by standard inexpensive batteries, it can be installed and used in an ambulance. The market opportunities for Pneuma may certainly come from a new niche market created by the needs of extra resources in intensive care units in case of a pandemic, especially in countries with very scarce health care system resources. 


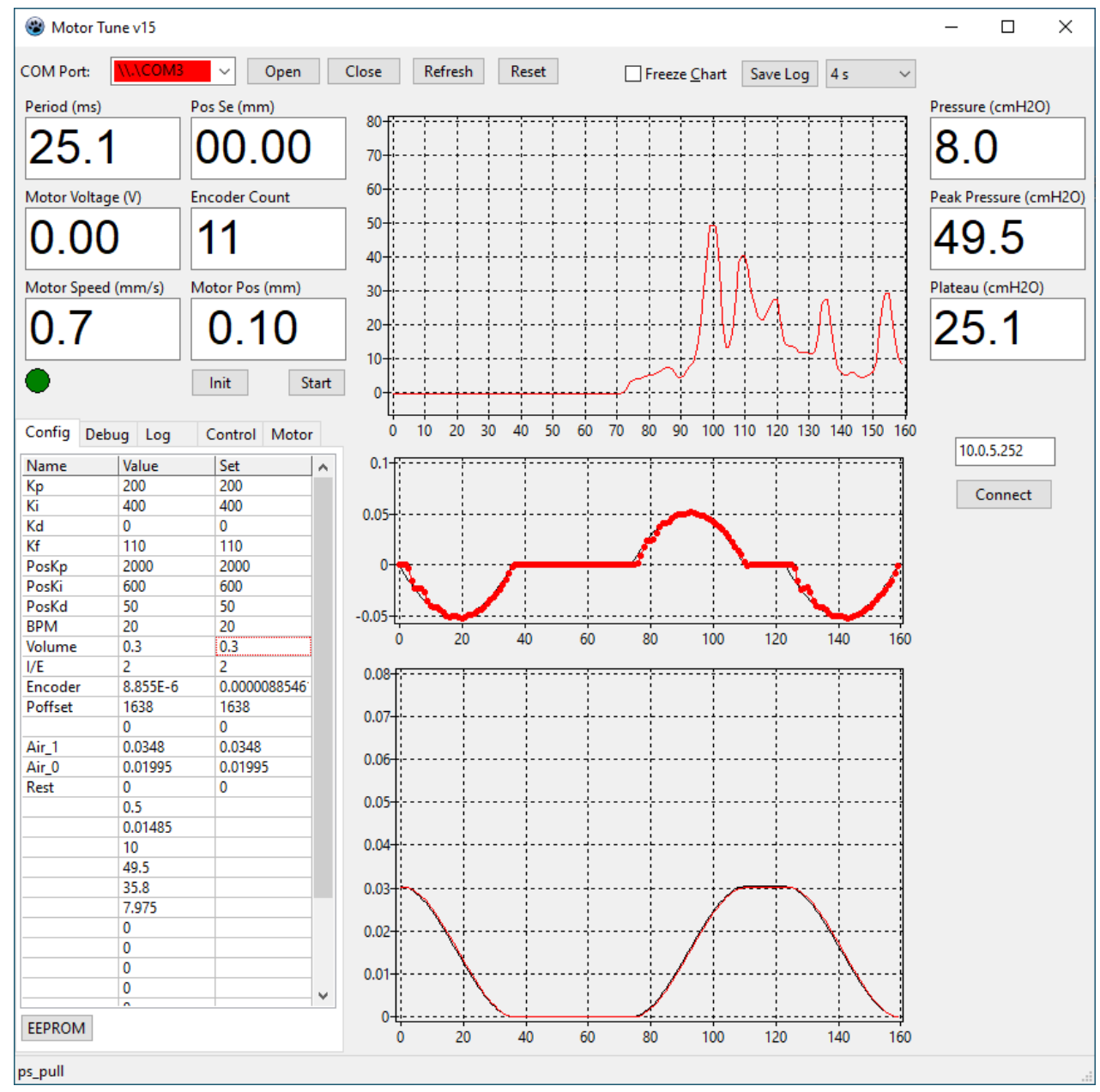

Fig. 10. Laptop application for setup, tuning and monitoring.

\section{Acknowledgements}

Since Pneuma team was much larger than the authors of this letter, the following team members should also be mentioned and acknowledged:

Coordination: João Claro (FEUP, INESC TEC);

Technology development: Alexandre Gomes (in a personal capacity), Ana Fontaínhas (in a personal capacity), Cláudia Rocha (INESC TEC), José Carlos Azevedo (INESC TEC), José Magalhães Lima (IPB, INESC TEC), Manuel Silva (ISEP, INESC TEC), Maria Nazaré Pinto (in a personal capacity), Mário Marinho da Silva (in a personal capacity), Paulo Paulo Jorge Marinho da Silva (in a personal capacity), Tiago Teixeira Pinto (in a personal capacity);

Consultants: Abel Nicolau (FMUP, CINTESIS), Carolina Sousa (CHUSJ), Altamiro Costa Pereira (FMUP, CINTESIS), Carlos Almeida (ISEP, INESC TEC), Carlos Ferreira (INESC TEC), Catarina Maia (FCUP, INESC TEC), Esaú Cardoso (IEP), Eurico Castro Alves (ICBAS, CHUP 
EPE), Frederico Carpinteiro (Adapttech), Henrique Salgado (FEUP, INESC TEC), Jorge Marvão (CHUP EPE), Luís Pessoa (FEUP, INESC TEC), Manuel Ricardo (FEUP, INESC TEC);

INESC TEC and the team wish to acknowledge the following companies and institutions:

- AIMMAP and FLAD, for being the sponsors supporting the manufacturing and logistic costs of the 200 Pneuma units;

- ARS-Norte, for their trust, support and guidance during the prototype development and testing;

- FMUP, for contributing with their facilities, equipment and human resources, and ICBAS, for making available their testing facilities;

- SELT (assembly and cabling), Toolpath (component redesign and manufacturing), and HeLuEm (laser cutting) should be acknowledged by the invaluable support to industrialization and manufacturing. Botnroll (electronics supplier) should be acknowledged for offering some components and low cost of the supplied material, as well as for the support in supplier procurement and fast delivery.

- The Foundation for Science and Technology, for the financial support to project number 82 under the special call RESEARCH4COVID19. 


\section{Biographies}

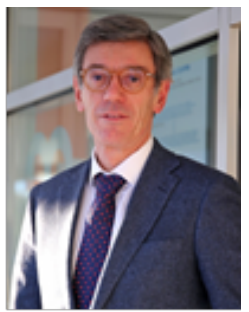

José M. Mendonça. José Manuel Mendonça, graduated in Electrical Engineering at the School of Engineering, University of Porto, in 1977. He worked in Brown, Boveri \& C.ie, Denmark Technical High School and EDP. He obtained his Ph.D in Electrical Engineering at Imperial College of Science and Technology, in 1986. From 1986 to 1996, he formed a research group in industrial systems engineering, publishing over 100 papers and supervising a large number of students. He gained leading experience in contract research with industry, namely at Fraunhofer IPA. He has been project leader of large EU projects, project reviewer, external advisor and National Delegate in various EU R\&D Programs. Over the next decade, he has been VP of the National Innovation Agency, CEO of the Ilídio Pinho Foundation and Chairman of Tech M5, Fibersensing and Kinematix. Since 2004 he is a Full Professor at the Department of Industrial Engineering and Management, School of Engineering, University of Porto, and since 2005 also CEO and Chairman of INESC TEC. He is a Fellow of the IC2 Institute, University of Texas, Austin, member of the High-Level Group of the Manufuture Platform, PI of UT Austin Portugal Program and Chairman of ForestWISE CoLAB.

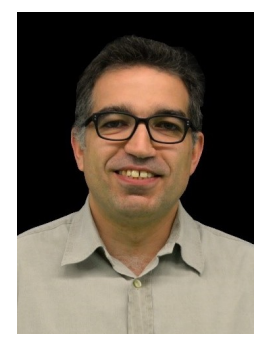

Nuno Cruz. Nuno Alexandre Cruz was born in Porto, Portugal, in 1970. He graduated in Electrical and Computer Engineering at the University of Porto (FEUP), Portugal, in 1993. He received the MSc. in Digital Systems Engineering from UMIST, UK, in 1994, and the $\mathrm{PhD}$ in Electrical and Computer Engineering from FEUP in 2016. He is currently a Research Coordinator at the Centre for Robotics and Autonomous Systems of INESC TEC, in Portugal. He is also an Assistant Professor at FEUP, where he has been teaching for over 20 years, and serves as a member of the Department Council. His research interests include marine robotics, underwater navigation systems, and efficient use of autonomous vehicles at sea. He has participated in numerous R\&D projects, both national and international, and has been the author or co-author of more than 100 publications in international journals, book chapters, and proceedings of conferences, with regular presentations in top international conferences. Dr. Cruz is a Senior Member of the IEEE Oceanic Engineering Society (a member since 1997), where he serves as an Associate Editor of the Journal of Oceanic Engineering, in the topics of AUV design, underwater navigation, acoustic navigation, and adaptive sampling.

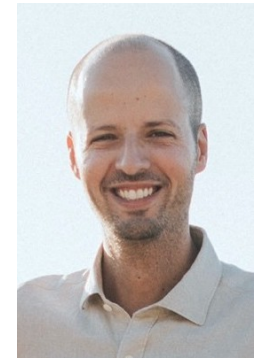

Daniel Vasconcelos. Daniel M. Vasconcelos was born in Espinho, Portugal in 1988. He received the M.S. degree in bioengineering from the the Faculty of Engineering of the University of Porto (FEUP) in 2011, the Ph.D. degree in biomedical sciences in 2017 from the Institute of Biomedical Sciences Abel Salazar - University of Porto, and the M.S. degree in innovation economics and management from the Faculty of Economics of the University of Porto (FEP) in 2017. From 2007 to 2017, he was a Research Assistant at INEB / i3S. He was Visiting Researcher at the Universite Paris 13 (2011) and at the Universitats Klinikum Heidelberg (2013). His research interest at that time was the immune response induced by implantable medical devices. He is the author of 9 scientific papers, all in Q1, and a book chapter on medical devices regulation and standards. He is invited professor at FEUP for medical technology development (Biodesign) and Economics and Management courses. Presently, Dr. Daniel is the Head of the Technology Licensing Office at INESC TEC. Additionally, he is the European IP Helpdesk Ambassador for Portugal and member of the renowned associations of technology transfer professionals ASTP and I3PM.

\section{ISSN 2183-0606}

http://www.open-jim.org

http://creativecommons.org/licenses/by/3.0 


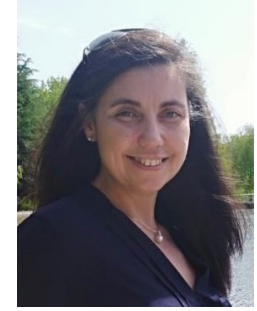

Carla Sá-Couto. Carla Sá-Couto was born in V. N. Gaia, Portugal, in 1977. She is a clinical simulation educator and researcher with a background in Biomedical Engineering. She is an integrated researcher at the Center for Health Technology and Services Research (CINTESIS), and director of the Biomedical Simulation Center of the Faculty of Medicine of University of Porto (CSB-FMUP). Together with her research and management activities, she is an affiliated professor at CSB-FMUP, being responsible for several simulation-based preand post-graduation courses. She is the Portuguese representative of the EuSim Group and coordinator of the Portuguese EuSim simulation instructor course. She was co-founder and former board member of the Portuguese Society of Simulation Applied to Healthcare (SPSim). Since 2017, she is serving as the chair of the scientific committee of the Society in Europe for Simulation Applied to Medicine (SESAM). Her current research interests are the development and testing of methodologies and tools for simulation based training, the integration of simulation in clinical teaching and training, and the transferability of non-technical skills training on healthcare provider's attitudes/behaviors and patient outcomes.

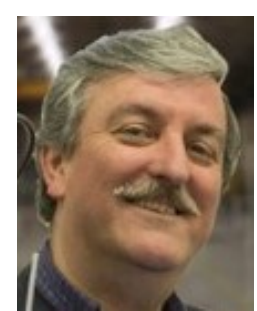

António P. Moreira. A. Paulo Moreira graduated with a degree in electrical engineering at the University of Oporto, in 1986. Then, he pursued graduate studies at University of Porto, obtaining a M.Sc. degree in electrical engineering - systems in 1991 and a Ph.D. degree in electrical engineering in 1998. Presently, he is Associate Professor with tenure at the Faculty of Engineering of the University of Porto and researcher and head of the Robotics and Intelligent Systems Centre at INESC TEC. His main research interests are process control and robotics.

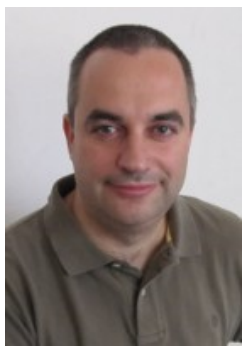

Paulo Costa. Paulo Costa graduated with a degree in electrical engineering at the University of Oporto, in 1991. Then, he pursued graduate studies at University of Porto, obtaining a M.Sc. degree in electrical engineering - systems in 1995 and a Ph.D. degree in electrical engineering in 2000. Presently, he is Assistant Professor with tenure at the Faculty of Engineering of the University of Porto and researcher at the Robotics and Intelligent Systems Centre at INESC TEC. His main research interests are modelling, simulation and robotics.

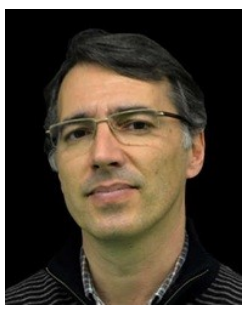

Hélio Mendonça. Hélio Sousa Mendonça was born in Porto, Portugal, in 1968. He graduated in Electrical and Computer Engineering at the Faculty of Engineering of the University of Porto (FEUP) in 1991. He received the MSc. in Electrical and Computer Engineering from the same University, in 1994, and the PhD in 2004. Currently, he is an Assistant Professor at FEUP and a Researcher at the Centre for Robotics in Industry and Intelligent Systems (CRIIS) of INESC TEC. His main interest areas are Embedded Systems; Wireless Sensor Networks and Robotics.

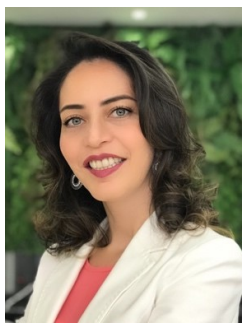

Ariane Pereira. Ariane R. Pereira was born in Maringá, Paraná, Brazil in 1982. She received the B.S. and M.S. degrees in Business Management from the Universidade Federal de Santa Catarina (UFSC), Florianópolis/Brazil, in 2013 and the Ph.D. degree in Industrial Engineering and Management from the Faculty of Engineering of the University of Porto/Portugal, in 2017. She is currently Head of the Innovation Management Business Area and Researcher Fellow at INESC P\&D BR, in which she started working as research fellow and project manager in 2018. As an author, she has published several papers in conferences, workshops, and journals. She has also been involved in national and international research projects, including the role of exploitation manager for an Industry 4.0 EU-BR project (2017-2020). Her major research interests are the Front End of Innovation; Entrepreneurship and Industry 4.0. She is also co-founder of C3Gi a people tech startup. 


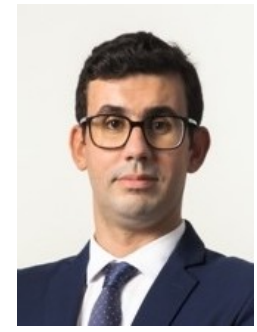

Zakaria Naimi. Mr. NAIMI Zakaria received his Engineer diploma in electrical engineering from the Ecole Mohammadia d'Ingénieurs in 2011. He joined in the same year the Research Institute for Solar Energy and New Energies - IRESEN as a power system design engineer. He co-designed the concept of the Green Energy Park - GEP and managed the implementation of the entire project. He coordinated and led national and international research and demonstration projects in the GEP. The scope of the activities covered solar technologies, smart grids and electric mobility. Few years later, he became Director of PV and Electrical Systems at IRESEN. In 2017, he joined the Moroccan Agency for Sustainable Energy (MASEN) as project manager of R\&D and Industrial integration. He managed research projects and developed industrial integration and local content programs for PV, storage and smart grid industry in Morocco and beyond. He set up and managed strategic alliances with national and international partners. In 2019, he joined the Green Energy Park as Manager.

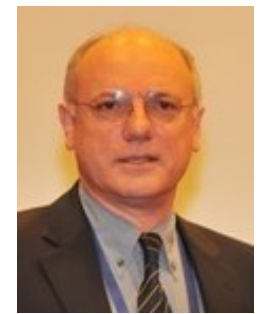

Vladimiro Miranda. Vladimiro Miranda (M'90-SM'04-F'06) received the Ph.D. degree in electrical engineering from the Faculty of Engineering of the University of Porto (FEUP), Porto, Portugal, in 1982.,In 1981, he joined FEUP and holds the position of Full Professor. He is currently Associate Director, with INESC TEC - INESC Technology and Science, an R\&D institute in Portugal, where he has been a Researcher since 1985. He is at the same time the President of INESC P\&D Brasil, in Brazil. He holds scientific advisory positions in several institutions, such as the IIT in Madrid, Spain, the IEE in San Juan, Argentina, IRESEN and GEP in Morocco and other. He has authored many papers and been responsible for many projects in areas related with the application of Computational Intelligence to power systems. Prof. Miranda was the 2013 recipient of the IEEE PES Ramakumar Family Renewable Energy Excellence Award and is an IEEE Distinguished Lecturer.

\section{ISSN 2183-0606}

